\title{
The impacts of tropical forest disturbance on species vital
}

\section{rates}

\author{
Cindy C.P. Cosset ${ }^{*}$, James J. Gilroy ${ }^{2}$, David P. Edwards ${ }^{1}$ \\ ${ }^{1}$ Department of Animal and Plant Sciences, University of Sheffield, S10 2TN, UK \\ ${ }^{2}$ School of Environmental Sciences, University of East Anglia, Norwich NR47TJ, UK \\ *Corresponding author.
}

Email address: ccpcosset@gmail.com

Running head: Species vital rates

Keywords: land-use change, survival, reproductive success, movement, selective logging, forest fragmentation, agriculture, fire

Article Impact Statement: Empirical research on demography across taxa and regions is lacking and between-species variation in demographic responses to land-use change is considerable.

\section{Abstract}

Tropical forests are experiencing enormous threats from deforestation and habitat degradation. Much of our knowledge on the impacts of these land-use changes on tropical species comes from studies examining patterns of richness and abundance. Demographic vital This article has been accepted for publication and undergone full peer review but has not been through the copyediting, typesetting, pagination and proofreading process, which may lead to differences between this version and the Version of Record. Please cite this article as doi: 10.1111/cobi.13182.

This article is protected by copyright. All rights reserved. 
rates (survival, reproduction and movement) can also be impacted by land-use change in a way that increases species vulnerability to local extinction, but in many cases these impacts may not be manifested in short-term changes in abundance or species richness. We assessed current knowledge and research effort concerning how land-use change affects species vital rates in tropical forest vertebrates. We find a general paucity of empirical research on demography across taxa and regions, with some biases towards mammals and birds, and land-use transitions including fragmentation and agriculture. There is also considerable between-species variation in demographic responses to land-use change, which could reflect trait-based differences in species sensitivity, complex context-dependencies (e.g. betweenregion variation) or inconsistency in methods used in studies. Efforts to improve our understanding of anthropogenic impacts on species demography are underway, but there is a need for increased research effort to fill knowledge-gaps in under-studied tropical regions and taxa. The lack of information on demographic impacts of anthropogenic disturbance makes it difficult to draw definite conclusions about the magnitude of threats to tropical ecosystems under anthropogenic pressures. Thus, determining conservation priorities and improving conservation effectiveness remains a challenge. 


\section{Tropical deforestation and degradation}

Despite a wealth of research identifying tropical deforestation and degradation as primary drivers of global biodiversity loss (Barlow et al. 2016, Gibson et al. 2011), most empirical work examines patterns of species richness and abundance across spatial or temporal gradients of anthropogenic impact (Gibson et al. 2011; Burivalova et al. 2014). Importantly, such patterns can mask underlying impacts on species that persist following land-use change. For example, forest degradation following selective logging might not affect a species' abundance in the short-term, but long-term population viability could be reduced via declines in survival or reproductive success (Srinivasan et al. 2015). Core drivers of overlooked impacts include when populations in degraded habitats are buffered by immigration from surrounding areas (Gilroy \& Edwards 2017), when high-quality habitats are occupied by dominant individuals that force others to occur in higher abundance in marginal habitats (Holt 1985), or when degradation causes declines in habitat quality without influencing the relative attractiveness of the habitat ('ecological traps', Gilroy \& Sutherland 2007).

To generate a robust understanding of the true long-term impacts of anthropogenicinduced land-use change on ecological communities requires understanding how underlying demographic vital rates, such as survival, reproductive success and movement (dispersal) change. Dispersal rate, for instance, can determine the ability of populations to persist in degraded and fragmented habitats (Fahrig 2007), and to traverse inhospitable barriers (Lees \& Peres 2009). Vital rates can thus better indicate the state of a population, as both population stability and viability are driven by demography (Saether \& Bakke 2000; Haridas et al. 2013). 
Here, we examine the state of current understanding of the impacts of tropical landuse change on species' vital rates to identify knowledge gaps and assess any general trends in responses. Such understanding can give us a better picture of the long-term resilience of species in degraded habitats. We assess demographic vital rates of terrestrial vertebrates (birds, mammals, reptiles and amphibians) in the tropics, exploring patterns of research effort across regions and taxonomic groups for four key land-use changes: forest conversion to agriculture, forest fragmentation, selective logging, and fire.

\section{Literature review methods}

We reviewed studies that assessed the impacts of anthropogenic disturbance on survival, reproductive success and movement in tropical forest vertebrate species (birds, mammals, reptiles and amphibians). For survival, we only included studies that calculated empirical estimates of survival rates from observed data (e.g. mark-recapture, telemetry studies). For simplicity, we define measures of reproductive success as any assessment of fecundity, breeding success or recruitment rate (including population growth rate). We defined movement studies as those considering dispersal rates (i.e. movements resulting in successful or unsuccessful gene flow) or temporary movement (e.g. foraging movements), since foraging is important for survival.

Using the online Web of Science database, studies were found using the key words: [degradation OR deforestation OR "habitat change" OR "land use" OR "habitat conversion"] AND [survival OR dispersal OR movement OR "population growth" OR "birth rate" OR "death rate" OR fecundity OR "breeding success" OR "clutch size" OR "reproductive success" OR "brood size" OR productivity OR lambda OR demography]. The search was refined by [tropic*] and either [logging], [agriculture], [fragmentation] or [fire]. This search 
was conducted from $6^{\text {th }}$ October 2016 to $20^{\text {th }}$ November 2016 . In total, 3076 studies were found using this keyword search. Of these, we selected studies for inclusion only if they were: (i) conducted in the tropical region (between $23.43706^{\circ} \mathrm{N}$ and $23.43706^{\circ} \mathrm{S}$ ); (ii) conducted in closed-canopy tropical forests, excluding studies in open, grassland dominated systems like Cerrado; (iii) studied only terrestrial tropical vertebrates; and (iv) assessed the impacts of anthropogenic disturbances using any measure of survival, demography and movement in their analyses. The COMADRE database (Salguero-Gomez et al. 2016) was also used to supplement the search. Of 71 studies found in the tropics, 64 studies met our criteria (see Appendix S1 for full list of studies; Fig 1 for distribution of studies across tropics). The remaining seven were conducted in open, grassland dominated systems. These 64 studies were separated into the different vital rates (survival, reproductive success, movement) and then classified by land-use disturbance (selective logging, agriculture, fragmentation, fire), tropical region (Neotropics, Afrotropics, Indomalayan tropics, Australasian tropics/Oceania) and study area elevation (lowland, sub-montane, montane). Studies that reported results for multiple rates, regions or land-use classes were counted for each class separately.

\section{Impacts of anthropogenic disturbances on vital rates}

Pan-tropically, we found a total of seven studies reporting impacts of anthropogenic disturbances on forest vertebrates using measures of survival, 22 using reproductive success and 40 using movement (see Table 1 for summary; Fig. 1). Overall, these totals highlight a paucity of information on how anthropogenic changes affect the vital rates of vertebrate biodiversity across the tropics. Studies were largely restricted to birds and mammals, with only $3 \%$ concerning amphibians and none on reptiles (Fig. 2d). For all three vital rate classes, deforestation for agriculture and forest fragmentation were the predominant anthropogenic 
impacts addressed by research, with far fewer studies considering selective logging or fire (Fig. 2). In the following sections, we examine general patterns and trends evident from studies concerning each anthropogenic impact class.

\section{Forest conversion to agriculture}

The rate of forest conversion to farmland in the tropics was around 7 million hectares annually from 2000 to 2010 (FAO 2016) and it is well established that this conversion produces strong negative impacts on tropical biodiversity (Edwards et al. 2014; Gibson et al. 2011). Agricultural conversion typically removes important food sources, breeding habitats and refugia from inhospitable climates (Fitzherbert et al. 2008). Nevertheless, low intensity farmland and polyculture landscapes can support a surprising amount of wildlife (Karp et al. 2011), particularly if crop plants themselves provide diverse food sources (Wickramasinghe et al. 2004).

Survival: We found only three studies assessing the impact of forest conversion to agriculture on survival rates (Newell 1999; VanderWerf 2004; Peery \& Pauli 2014). In two cases, conversion did not significantly affect survival: Hawaiian 'Elepaio Chasiempis sandwichensis (VanderWerf 2004) and Hoffmann's two-toed sloths Choloepus hoffmanni (Peery \& Pauli 2014), as the agricultural lands in question apparently provided sufficient resources to fulfil niche requirements, and the species exhibited plasticity in their foraging behaviors (Vaughan et al. 2007). However, studies showed that deforestation reduced the survival of two other mammal species, due to increased predation and poor habitat quality in the agricultural systems.

Reproductive rates: We found eight studies evaluating the impacts of deforestation on reproductive rates, again concerning bird and mammal species. The effects of deforestation 
on reproductive rates were species-dependent where four studies showed declines in breeding success of birds and mammals, three did not detect any impacts on avian nest survival and one study on Hoffmann's two-toed sloths Choloepus hoffmanni and brown-throated threetoed sloths Bradypus variegatus found variations in population growth rates. Conversion to agriculture can have little impact on reproductive rates if species are able to utilize resources within the novel habitat (Sekercioglu et al. 2015), or if other limiting factors such as predator populations are controlled by human activities (Bobo \& Waltert 2011).

Movement: We found nineteen studies examining the impacts of animal movements in agricultural lands after deforestation; two on amphibians, and the rest on birds and mammals. Again, these studies found a varied range of effects of conversion on movement, from less (Ibarra-Macias et al. 2011) to no effect (Medina et al. 2007) to more movement (Powell et al. 2016). Factors that can cause changes in movement behavior include increased competition, increased predation (Lees \& Peres 2009; Shadbolt \& Ragai 2010) and higher mortality risks from inhospitable microclimates (Lees \& Peres 2008). Alternatively, species movement can be unaffected by agriculture if farmlands provide adequate resources (Luck \& Daily 2003) or if species are already highly vagile (Estrada et al. 1993). 


\section{Forest Fragmentation}

Deforestation fragments the remaining forest, creating abundant edges impacted by hotter, windier and drier climates (Laurance et al. 2002). Detailed autoecological studies have shown that many forest-dependent species are unable to persist within forest patches and/or cross gaps (Ferraz et al. 2003; Lees \& Peres 2009), such that smaller and more isolated fragments have strong negative impacts on species diversity and abundance (Ferraz et al. 2003; Russildi et al. 2016). Furthermore, increased edge effects mean that fragmentation can alter the community composition of landscapes, with shifts from interior-specialists to edgespecialists and generalists (Laurance et al. 2002; Magnago et al. 2014, Pfeifer et al. 2017).

Survival: We found four studies assessing species survival on birds in fragmented forest landscapes. Fragmentation resulted in reduced survival in 24 species, relative to contiguous forest, likely caused by increased predation, reduced resources, and higher mortality risks when vagile species traverse the matrix (Shadbolt \& Ragai 2010; Lees \& Peres 2008). Conversely, eight bird species exhibited no negative effects from fragmentation. The survival of white-starred robins Pogonocichla stellata in Southeast Kenya, for example, was similar in all fragment sizes (Githiru \& Lens 2006). However, the major causes of mortality varied with fragment size: mortality associated with dispersal was more prominent in larger fragments, whereas mortality from nest predation was more important in smaller fragments.

Reproductive rates: We found fifteen studies assessing the impacts of forest fragmentation on reproductive rates, 14 using birds and one using mammals (Umapathy et al. 2011). The majority of these studies examined reproductive success using nest predation experiments. Common detrimental effects of fragmentation on reproductive rates include 
increased nest predation (Stirnemann et al. 2015) and negative population growth rates (Korfanta et al. 2012). Conversely, fragmentation had little effect on breeding rates in a few cases. Reproductive rates can be robust to fragmentation if key resources remain intact inside fragments, or if vagile species can utilise the matrix to meet their foraging needs (Lees \& Peres 2009).

Movement: Forest fragmentation impacts on movement were examined in 28 studies, considering birds and mammals with only one study on frogs (Robinson et al. 2013). Some species exhibited changes in their movement patterns in fragmented landscapes relative to contiguous forests. For instance, understorey birds in Central Amazonian Brazil have their movement restricted by open narrow roads and these roads act as territorial boundaries (Develey \& Stouffer 2001). This could be due to intolerance of crossing fragment edges (Laurance et al. 2004), higher predation risks or increased competition from matrix-tolerant species that invade forest edges (Lees \& Peres 2009; Shadbolt \& Ragai 2010). However, other studies showed limited effects of fragmentation on movement. This could reflect species using the matrix for refuge (Robinson et al. 2013) or food (Estrada \& Coates-Estrada 2002; Luck \& Daily 2003), allowing species to traverse the matrix (Manning et al. 2006; Lees \& Peres 2009).

\section{Selective Logging}

Over 20 percent of tropical forests were degraded by selective logging from 2000 to 2005 (Asner et al. 2009), yet selective logging has minimal negative impacts on biodiversity, often allowing the retention of similar species richness to primary forest (Gibson et al. 2011; Putz et al. 2012; Edwards et al. 2014), including species of conservation concern (Edwards et al. 2011). However, selective logging changes community composition (Chapman et al. 
2000; Edwards et al. 2011, 2014) and can have more adverse effects on biodiversity at higher logging intensities (Burivalova et al. 2014; Martin et al. 2015) or when using poor ('conventional') logging techniques (Bicknell et al. 2014).

Survival: We found only one study that evaluated the impacts of selective logging on avian survival (VanderWerf 2004). No impact of selective logging was found on the survival of Hawaiian 'Elepaio bird populations (VanderWerf 2004) despite logged sites having a lower estimated carrying capacity. In this case, populations appeared to buffer disturbance impacts by increasing their territory sizes.

Reproductive rates: We found four studies examining the impacts of selective logging on reproductive rates, again all concerning birds. These showed varying responses to logging, including increased nest predation rates (Cooper \& Francis 1998; Pangau-Adam et al. 2006) due to increased forest access for predators (Andren \& Angelstam 1988) and mesopredator release after logging (Crooks \& Soule 1999). Positive or neutral responses were also found in some cases, including no change in breeding success in logged habitats relative to unlogged (VanderWerf 2004; Yap et al. 2007).

Movement: We found seven studies examining the effects of selective logging on mammal and bird movements. Again, these studies found varying responses, with some species exhibiting no change and others showing inhibitions or movement changes. Species movement can be affected by selective logging if the exposed forest gaps and logging roads have harsher microclimates that deter species, or if changes in forest structure alter movement strategies (Cunha \& Vieira 2002). Alternatively, movement can remain unaffected if logged forests provide suitable habitat or if there is plasticity in species behaviours (Wells et al. 2008). 


\section{Forest Fire}

Forest degradation increases fire risk by increasing fuel load and exposing the forest to more wind and sun, which increases desiccation (Peres et al. 2006, Nepstad et al. 2008). El Niño drought-induced fires severely degraded $\sim 20$ million hectares of tropical forests in 1997-98 (Cochrane 2003) and millions of hectares in 2015-16. Burning can result in severe tree mortality, leading to the replacement of forest interior animals and hardwood emergent trees with generalist wildlife and pioneer plants (Barlow \& Peres 2004; Brando et al. 2014). Fire typically reduces bird species abundance and richness, changing community composition (Barlow \& Peres 2004, 2008; Slik \& Van Balen 2006).

We found no studies assessing survival and reproductive rates with respect to fireprone tropical forest landscapes. One study showed significant changes in movement behaviour of northern bettongs after fire (Vernes \& Haydon 2001), indicating behavioural plasticity in movement in response to habitat alteration, though the potential consequences for demography were unclear. It is crucial that we better understand the implications of fire on species vital rates, given the drastic effects of fire on tropical forest structure, resources, and biodiversity.

\section{Research effort by region \& elevation}

Our review highlighted some important regional and elevational biases in research (Fig 1). Survival, reproductive rate and movement studies spanned all tropical regions, but there was a preponderance of studies from the Neotropics (total $=35$; survival $=3$; reproductive rate $=7$; movement $=25$ ), with less than half the number of studies in the Afrotropics (total=16; survival $=2$; reproductive rate $=8$; movement $=6$ ), less than a third in the Indomalayan tropics (total $=10$; survival $=0$; reproductive rate $=5$; movement $=5$ ) and less than a quarter in the 
Australasian/Oceanic tropics (total $=8$; survival=2; reproductive rate $=2$; movement $=4$ ) (Fig. 1; Table 1). All three vital rates were studied at all elevational classes, although more studies were conducted in the lowlands (50) compared to sub-montane (16) or montane elevations (11), despite uplands harbouring high endemism and extinction risk (Appendix S2). This trend is expected, however, being broadly in line with the total area covered by each elevational class across the tropics.

\section{Discussion \& Future Directions}

Deforestation and forest degradation are key drivers of the current extinction crisis (Gibson et al. 2011; Barlow et al. 2016), but most knowledge of their impacts on biodiversity comes from one-off censuses conducted across a short time frame used to generate estimates of species richness and abundance patterns (Gibson et al. 2011; Burivalova et al. 2014; Edwards et al. 2014; Barlow et al. 2016). However, species richness and abundance may change over time if the degraded habitat is in extinction debt or if it recovers. Importantly, these abundance-based metrics can sometimes mask more severe underlying longer-term impacts on species persistence (Srinivasan et al. 2015; Gilroy \& Edwards 2017). The fact that so few studies have been carried out in the tropics suggests that anthropogenic impacts might be underestimated. This might mean that the true biodiversity impact of anthropogenic disturbances like selective logging and low-intensity agriculture are much more significant than currently recognized, and thus that greater efforts are needed to assess impacts on demographic vital rates.

We find wide variation in observed vital rate responses to anthropogenic change across tropical vertebrates. This might reflect the variation in species-specific responses to disturbance, with many species possessing traits allowing them to persist in novel 
environments, whilst others are more vulnerable (Isaac \& Cowlishaw 2004). However, we caution against making definite conclusions regarding these trends due to the different natures of these studies and varied methodologies, which makes direct comparison impossible. Furthermore, vital rate responses can vary regionally among populations of the same species (Frederiksen et al. 2005). Vital rate changes in species have been linked to both abiotic (soil nutrients, light availability, etc.) and biotic (competition, predation, etc.) processes at local scales, which brings further complexity to efforts in understanding and predicting land-use impacts (Ehrlen \& Morris 2015). Many studies had small sample sizes (eg. Suarez-Rubio et al. 2015), because rarer or more elusive species were targeted, or study species inhabited inaccessible areas.

It is common practice to extrapolate a species' vital rate responses from a few locations to a wider area (Sæther et al. 2005), since it is not possible to sample every species in every location. However, the robustness of these extrapolation approaches has seldom been tested, and it is unclear which metrics are best used for extrapolating across populations. Coutts et al. (2016) showed that extrapolation is possible but at limited spatial scales, finding that demographic rates cannot be robustly extrapolated further than $20 \mathrm{~km}$ geographically. Extrapolation between species is further limited, with robust extrapolation unlikely for species pairs where phylogenetic distance exceeds 10 million years since the last common ancestor (Coutts et al. 2016). While this does not mean that it is impossible to apply the responses of one population over a larger range or to use rules of thumb derived from one species to make predictions about others, it suggests that more studies are required, sampling over larger areas and across more taxa, if we are to properly understand how underlying vital rates respond to land-use change. 
We focused only on terrestrial vertebrates, though the research paucity identified will likely extend to other taxa. Land-use change impacts on tropical plant demography, in particular, may be critically important in determining long-term ecological resilience following anthropogenic impact. Terrestrial vertebrates are important pollinators and dispersers for plants and are likely to drive the vital rates of plants (Kremen et al. 2007; Peres et al. 2016). For example, fragmentation can be detrimental to plant vital rates (Bruna et al. 2002; Laurance et al. 1998) if their pollinators and seed dispersers are negatively affected (Regan et al. 2015, Peres et al. 2016) or seed predation increases (Curran \& Webb 2000; Scariot 2000).

It is difficult to reliably compare between demographic studies as there is a lack of consistency in the methods and metrics used. This lack of consistency combined with the paucity of vital rate data make it difficult to understand or predict patterns in species' demographic responses to environmental change (Sutherland et al. 2013). One effort to promote the standardization of data is the COMPADRE Plant Matrix (Salguero-Gomez et al. 2015) and COMADRE Animal Matrix (Salguero-Gomez et al. 2016) databases. These open data repositories contain matrix population models for both plant and animal species that aim to encourage more comparative studies. So far, COMPADRE has facilitated more than 35 comparative studies since its establishment in 1990 (eg. Stott et al. 2011). By compiling and standardizing vital rate data, ecologists will be better able to identify gaps in our knowledge and thus broaden the coverage of data across species and geographical locations.

\section{A role for indirect evidence?}

As direct measurement of species vital rates to determine the long-term risk posed by tropical forest disturbance are relatively rare, a key question is the degree to which it is 
possible to use indirect evidence to infer impacts. One method is to use count-based abundance and density trends to infer demographic change (Durant et al. 2011), especially when data are collected over a long-time series (Durant et al. 2011; Keith et al. 2015). However, long-term trends in abundance and density may still mask negative demographic impacts in situations that involve source-sink dynamics (Gilroy \& Edwards 2017), where population density can be maintained despite reductions in population growth rate by immigration of individuals from surrounding habitat (Pulliam 1988). Furthermore, density can be higher in disturbed habitats, despite declining demographics, from processes such as competitive exclusion ('dominance hierarchies', Holt 1985), the crowding effect (Debinski \& Holt 2000) or individuals mistaking poorer quality habitats as being more attractive ('ecological traps’, Gilroy \& Sutherland 2007).

Another potential method is to use observed contractions in species ranges due to land-use change as a predictor for increased species' extinction risk (Harris \& Pimm 2008). For instance, incorporating geospatial data by refining species geographical ranges using elevation maps and the extent of remaining habitat cover could improve the accuracy of predictions in species extinction risk analyses (Ocampo-Peñuela et al. 2016). Using this approach, Ocampo-Peñuela et al. (2016) assessed the extinction risk posed by land-use change for 586 tropical forest bird species from six regions (Southeast Asia, Sumatra, Madagascar, Colombia, Central America and Brazil) and showed that 210 species were more at-risk than previously thought .

Evaluating change in suitable habitat quality and area can also allow inferences of changes in species abundance and ranges to be drawn, providing insights into resilience under changing habitat conditions (Jennings 2000, Harris \& Pimm 2008). Such regular assessments are especially important for tropical species, where land-use change occurs rapidly (Barlow et 
al. 2016). Although Negret et al. (2015) only conducted a one-off assessment of the range size of black tinamou (Tinamus osgoodi hershkovitzi), it revealed that their habitats are increasingly degraded by logging, hunting and agricultural activities, thus threatening the species with extinction despite populations currently occurring at high densities. Such data are important for providing a better understanding of the future resilience of species.

In conclusion, the current paucity of data makes it difficult to draw definite conclusions about the state of many tropical forest ecosystems, potentially influencing the robustness of conservation prioritization and management efficacy. We call for significant increases in long-term research efforts to measure demographic responses in a far wider variety of taxa, regions and habitat types across the tropics. Such data are also critical to assess the reliability of predictions made from indirect evidence, and may ultimately permit greater confidence, under certain circumstances at least, in the use of those forms of data to infer demographic change. Both would greatly aid the development of conservation approaches to reduce the impacts of land-use change through more sustainable natural resource use and improved protected area design throughout the tropics.

\section{Acknowledgments}

We thank the Leverhulme Centre for Advanced Biological Modelling for a $\mathrm{PhD}$ studentship awarded to C.C.P.C.

\section{Supporting Information}

Complete list of studies on vital rates (Appendix S1) and number of studies with positive, negative and varying responses to land-use change, grouped by elevation (Appendix S2) are available online. The authors are solely responsible for the content and functionality of these 
materials. Queries (other than absence of the material) should be directed to the

corresponding author.

\section{Literature Cited}

Andren H, Angelstam P. 1988. Elevated predation rates as an edge effect in habitat islands experimental-evidence. Ecology 69:544-547.

Asner GP, Broadbent EN, Oliveira PJC, Keller M, Knapp DE, Silva JNM. 2006. Condition and fate of logged forests in the Brazilian Amazon. Proceedings of the National Academy of Sciences of the United States of America 103:12947-12950.

Asner GP, Rudel TK, Aide TM, Defries R, Emerson R. 2009. A Contemporary Assessment of Change in Humid Tropical Forests. Conservation Biology 23:1386-1395.

Barlow J, et al. 2016. Anthropogenic disturbance in tropical forests can double biodiversity loss from deforestation. Nature 535:144-159.

Barlow J, Peres CA. 2004. Avifaunal responses to single and recurrent wildfires in Amazonian forests. Ecological Applications 14:1358-1373.

Bicknell JE, Struebig MJ, Edwards DP, Davies ZG. 2014. Improved timber harvest techniques maintain biodiversity in tropical forests. Current Biology 24:R1119R1120.

Bobo KS, Waltert M. 2011. Artificial bird nest predation along a forest conversion gradient in Cameroon. Ecotropica 17:21-29.

Brando PM, et al. 2014. Abrupt increases in Amazonian tree mortality due to drought-fire interactions. Proceedings of the National Academy of Sciences of the United States of America 111:6347-6352.

Bruna EM. 2002. Effects of forest fragmentation on Heliconia acuminata seedling recruitment in central Amazonia. Oecologia 132:235-243.

Burivalova Z, Sekercioglu CH, Koh LP. 2014. Thresholds of Logging Intensity to Maintain Tropical Forest Biodiversity. Current Biology 24:1893-1898.

Cartwright SJ, Nicoll MAC, Jones CG, Tatayah V, Norris K. 2014. Agriculture modifies the seasonal decline of breeding success in a tropical wild bird population. Journal of Applied Ecology 51:1387-1395.

Chapman CA, Balcomb SR, Gillespie TR, Skorupa JP, Struhsaker TT. 2000. Long-term effects of logging on African primate communities: a 28-year comparison from Kibale National Park, Uganda. Conservation Biology 14:207-217.

Cochrane MA. 2003. Fire science for rainforests. Nature 421:913-919.

Cooper DS, Francis CM. 1998. Nest predation in a Malaysian lowland rain forest. Biological Conservation 85:199-202.

Coutts SR, Salguero-Gómez R, Csergő AM, Buckley YM. 2016. Extrapolating demography with climate, proximity and phylogeny: approach with caution. Ecology Letters 19:1429-1438. 
Crooks KR, Soule ME. 1999. Mesopredator release and avifaunal extinctions in a fragmented system. Nature 400:563-566.

Cunha AA, Vieira MV. 2002. Support diameter, incline, and vertical movements of four didelphid marsupials in the Atlantic forest of Brazil. Journal of Zoology 258:419-426.

Curran LM, Webb CO. 2000. Experimental tests of the spatiotemporal scale of seed predation in mast-fruiting Dipterocarpaceae. Ecological Monographs 70:129-148.

Debinski DM, Holt RD. 2000. A survey and overview of habitat fragmentation experiments. Conservation Biology 14:342-355.

Develey PF, Stouffer PC. 2001. Effects of roads on movements by understory birds in mixedspecies flocks in central Amazonian Brazil. Conservation Biology 15:1416-1422.

Durant SM, Craft ME, Hilborn R, Bashir S, Hando J, Thomas L. 2011. Long-term trends in carnivore abundance using distance sampling in Serengeti National Park, Tanzania. Journal of Applied Ecology 48:1490-1500.

Edwards DP, Larsen TH, Docherty TDS, Ansell FA, Hsu WW, Derhe MA, Hamer KC, Wilcove DS. 2011. Degraded lands worth protecting: the biological importance of Southeast Asia's repeatedly logged forests. Proceedings of the Royal Society BBiological Sciences 278:82-90.

Edwards DP, et al. 2014. Selective-logging and oil palm: multi-taxon impacts, biodiversity indicators, and trade-offs for conservation planning. Ecological Applications 24: 2029-2049.

Ehrlen J, Morris WF. 2015. Predicting changes in the distribution and abundance of species under environmental change. Ecology Letters 18:303-314.

Estrada A, Coates-Estrada R. 2002. Bats in continuous forest, forest fragments and in an agricultural mosaic habitat-island at Los Tuxtlas, Mexico. Biological Conservation 103:237-245.

Estrada A, Coates-Estrada R, Meritt D. 1993. Bat species richness and abundance in tropical rainforest fragments and in agricultural habitats at Los-Tuxtlas, Mexico. Ecography 16:309-318.

Fagan ME, DeFries RS, Sesnie SE, Arroyo-Mora JP, Chazdon RL. 2016. Targeted reforestation could reverse declines in connectivity for understory birds in a tropical habitat corridor. Ecological Applications 26:1456-1474.

Fahrig L. 2007. Non-optimal animal movement in human-altered landscapes. Functional Ecology 21:1003-1015.

FAO. 2016. State of the World's Forests 2016. Forests and agriculture:land-use challenges and opportunities, Rome.

Ferraz G, Russell GJ, Stouffer PC, Bierregaard RO, Pimm SL, Lovejoy TE. 2003. Rates of species loss from Amazonian forest fragments. Proceedings of the National Academy of Sciences of the United States of America 100:14069-14073.

Fitzherbert EB, Struebig MJ, Morel A, Danielsen F, Bruhl CA, Donald PF, Phalan B. 2008. How will oil palm expansion affect biodiversity? Trends in Ecology \& Evolution 23:538-545. 
Frederiksen M, Harris MP, Wanless S. 2005. Inter-population variation in demographic parameters: a neglected subject? Oikos 111:209-214.

Gibson L, et al. 2011. Primary forests are irreplaceable for sustaining tropical biodiversity. Nature 478:378-381.

Gilroy JJ, Edwards DP. 2017. Source-sink dynamics: a neglected problem for landscape-scale biodiversity conservation. Current Landscape Ecology Reports 2:51-60.

Gilroy JJ, Sutherland WJ. 2007. Beyond ecological traps: perceptual errors and undervalued resources. Trends in Ecology \& Evolution 22:351-356.

Githiru M, Lens L. 2006. Annual survival and turnover rates of an afrotropical robin in a fragmented forest. Biodiversity and Conservation 15:3315-3327.

Githiru M, Lens L, Cresswell W. 2005. Nest predation in a fragmented Afrotropical forest: evidence from natural and artificial nests. Biological Conservation 123:189-196.

Haridas CV, Prendeville HR, Pilson D, Tenhumberg B. 2013. Response of population size to changing vital rates in random environments. Theoretical Ecology 6:21-29.

Harris G, Pimm SL. 2008. Range size and extinction risk in forest birds. Conservation Biology 22: 163-171.

Holt RD. 1985. Population-dynamics in 2-patch environments - some anomalous consequences of an optimal habitat distribution. Theoretical Population Biology 28:181-208.

Ibarra-Macias A, Robinson WD, Gaines MS. 2011. Experimental evaluation of bird movements in a fragmented Neotropical landscape. Biological Conservation 144:703712.

Isaac NJB, Cowlishaw G. 2004. How species respond to multiple extinction threats. Proceedings of the Royal Society B-Biological Sciences 271:1135-1141.

Jennings MD. 2000. Gap analysis: concepts, methods and recent results. Landscape Ecology 15:5-20.

Karp DS, Ziv G, Zook J, Ehrlich PR, Daily GC. 2011. Resilience and stability in bird guilds across tropical countryside. Proceedings of the National Academy of Sciences of the United States of America 108: 21134-21139.

Keith D, et al. 2015. Temporal correlations in population trends: Conservation implications from time-series analysis of diverse animal taxa. Biological Conservation 192:247257.

Korfanta NM, Newmark WD, Kauffman MJ. 2012. Long-term demographic consequences of habitat fragmentation to a tropical understory bird community. Ecology 93:25482559.

Kremen C, et al. 2007. Pollination and other ecosystem services produced by mobile organisms: a conceptual framework for the effects of land-use change. Ecology Letters 10:299-314.

Laurance SGW, Stouffer PC, Laurance WF. 2004. Effects of road clearings on movement patterns of understory rainforest birds in central Amazonia. Conservation Biology 18:1099-1109. 
Laurance WF, Ferreira LV, Rankin-De Merona JM, Laurance SG. 1998. Rain forest fragmentation and the dynamics of Amazonian tree communities. Ecology 79:20322040 .

Laurance WF, Lovejoy TE, Vasconcelos HL, Bruna EM, Didham RK, Stouffer PC, Gascon C, Bierregaard RO, Laurance SG, Sampaio E. 2002. Ecosystem decay of Amazonian forest fragments: A 22-year investigation. Conservation Biology 16:605-618.

Lees AC, Peres CA. 2008. Avian life-history determinants of local extinction risk in a hyperfragmented neotropical forest landscape. Animal Conservation 11:128-137.

Lees AC, Peres CA. 2009. Gap-crossing movements predict species occupancy in Amazonian forest fragments. Oikos 118:280-290.

Luck GW, Daily GC. 2003. Tropical countryside bird assemblages: Richness, composition, and foraging differ by landscape context. Ecological Applications 13:235-247.

Magnago LFS, Edwards DP, Edwards FA, Magrach A, Martins SV, Laurance WF. 2014. Functional attributes change but functional richness is unchanged after fragmentation of Brazilian Atlantic forests. Journal of Ecology 102:475-485.

Manning AD, Fischer J, Lindenmayer DB. 2006. Scattered trees are keystone structures Implications for conservation. Biological Conservation 132:311-321.

Martin PA, Newton AC, Pfeifer M, Khoo M, Bullock JM. 2015. Impacts of tropical selective logging on carbon storage and tree species richness: A meta-analysis. Forest Ecology and Management 356:224-233.

Medina A, Harvey CA, Merlo DS, Vilchez S, Hernandez B. 2007. Bat diversity and movement in an agricultural landscape in Matiguas, Nicaragua. Biotropica 39:120128.

Negret PJ, Garźon O, Stevenson PR, Laverde-R O. 2015. New ecological information for the Black Tinamou (Tinamus osgoodi hershkovitzi). The Auk 132: 533-539.

Nepstad DC, Stickler CM, Soares-Filho B, Merry F. 2008. Interactions among Amazon land use, forests and climate: prospects for a near-term forest tipping point. Phil Trans R Soc Lond B Biol Sci 363:1737-1746.

Newell GR. 1999. Responses of Lumholtz's tree-kangaroo (Dendrolagus lumholtzi) to loss of habitat within a tropical rainforest fragment. Biological Conservation 91:181-189.

Nowakowski AJ, Jimenez BO, Allen M, Diaz-Escobar M, Donnelly MA. 2013. Landscape resistance to movement of the poison frog, Oophaga pumilio, in the lowlands of northeastern Costa Rica. Animal Conservation 16:188-197.

Ocampo-Peñuela N, Jenkins CN, Vijay V, Li BV, Pimm SL. 2016. Incorporating explicit geospatial data shows more species at risk of extinction than the current Red List. Science Advances 2: e1601367.

Pangau-Adam MZ, Waltert M, Muhlenberg M. 2006. Nest predation risk on ground and shrub nests in forest margin areas of Sulawesi, Indonesia. Biodiversity and Conservation 15:4143-4158.

Peery MZ, Pauli JN. 2014. Shade-grown cacao supports a self-sustaining population of twotoed but not three-toed sloths. Journal of Applied Ecology 51:162-170. 
Peres CA, Barlow J, Laurance WF. 2006. Detecting anthropogenic disturbance in tropical forests. Trends in Ecology \& Evolution 21:227-229.

Peres CA, Emilio T, Schietti J, Desmouliere SJM, Levi T. 2016. Dispersal limitation induces long-term biomass collapse in overhunted Amazonian forests. Proceedings of the National Academy of Sciences of the United States of America 113:892-897.

Pfeifer M, et al. 2017. Creation of forest edges has a global impact on forest vertebrates. Nature 551:187-191.

Powell LL, Wolfe JD, Johnson EI, Stouffer PC. 2016. Forest recovery in post-pasture Amazonia: Testing a conceptual model of space use by insectivorous understory birds. Biological Conservation 194:22-30.

Pulliam HR. 1988. Sources, sinks, and population regulation. American Naturalist 132:652661.

Putz FE, et al. 2012. Sustaining conservation values in selectively logged tropical forests: the attained and the attainable. Conservation Letters 5:296-303.

Regan EC, Santini L, Ingwall-King L, Hoffmann M, Rondinini C, Symes A, Taylor J, Butchart SHM. 2015. Global trends in the status of bird and mammal pollinators. Conservation Letters 8:397-403.

Russildi G, Arroyo-Rodriguez V, Hernandez-Ordonez O, Pineda E, Reynoso VH. 2016. Species- and community-level responses to habitat spatial changes in fragmented rainforests: assessing compensatory dynamics in amphibians and reptiles. Biodiversity and Conservation 25:375-392.

Saether BE, Bakke O. 2000. Avian life history variation and contribution of demographic traits to the population growth rate. Ecology 81:642-653.

Saether BE, et al. 2005. Time to extinction of bird populations. Ecology 86:693-700.

Salguero-Gomez R, et al. 2016. COMADRE: a global data base of animal demography. Journal of Animal Ecology 85:371-384.

Salguero-Gomez R, et al. 2015. The COMPADRE Plant Matrix Database: an open online repository for plant demography. Journal of Ecology 103:202-218.

Scariot A. 2000. Seedling mortality by litterfall in Amazonian forest fragments. Biotropica 32:662-669.

Sekercioglu CH, Loarie SR, Oviedo-Brenes F, Mendenhall CD, Daily GC, Ehrlich PR. 2015. Tropical countryside riparian corridors provide critical habitat and connectivity for seed-dispersing forest birds in a fragmented landscape. Journal of Ornithology 156:S343-S353.

Shadbolt AB, Ragai R. 2010. Effects of habitat fragmentation on the movement patterns and dispersal ability of the brown spiny rat (Maxomys rajah) in the Planted Forest Zone of Sarawak, Eastern Malaysia. Biodiversity and Conservation 19:531-541.

Slik JWF, Van Balen S. 2006. Bird community changes in response to single and repeated fires in a lowland tropical rainforest of eastern Borneo. Biodiversity\& Conservation 15: 4425-4451.

Srinivasan U, Hines JE, Quader S. 2015. Demographic superiority with increased logging in tropical understorey insectivorous birds. Journal of Applied Ecology 52:1374-1380. 
Stirnemann RL, Potter MA, Butler D, Minot EO. 2015. Compounding effects of habitat fragmentation and predation on bird nests. Austral Ecology 40:974-981.

Stott I, Townley S, Hodgson DJ. 2011. A framework for studying transient dynamics of population projection matrix models. Ecology Letters 14:959-970.

Sutherland WJ, et al. 2013. Identification of 100 fundamental ecological questions. Journal of Ecology 101:58-67.

Umapathy G, Hussain S, Shivaji S. 2011. Impact of Habitat Fragmentation on the Demography of Lion-tailed Macaque (Macaca silenus) Populations in the Rainforests of Anamalai Hills, Western Ghats, India. International Journal of Primatology 32:889900.

VanderWerf EA. 2004. Demography of Hawai'i 'Elepaio: Variation with habitat disturbance and population density. Ecology 85:770-783.

Vaughan C, Ramirez O, Herrera G, Guries R. 2007. Spatial ecology and conservation of two sloth species in a cacao landscape in limon, Costa Rica. Biodiversity and Conservation 16:2293-2310.

Vernes K, Haydon DT. 2001. Effect of fire on northern bettong (Bettongia tropica) foraging behaviour. Austral Ecology 26:649-659.

Wells K, Kalko EKV, Lakim MB, Pfeiffer M. 2008. Movement and ranging patterns of a tropical rat (Leopoldamys sabanus) in logged and unlogged rain forests. Journal of Mammalogy 89:712-720.

Wickramasinghe LP, Harris S, Jones G, Jennings NV. 2004. Abundance and Species Richness of Nocturnal Insects on Organic and Conventional Farms: Effects of Agricultural Intensification on Bat Foraging. Conservation Biology 18:1283-1292.

Yap CAM, Sodhi NS, Peh KSH. 2007. Phenology of tropical birds in Peninsular Malaysia: Effects of selective logging and food resources. Auk 124:945-961. 
TABLE 1. Number of studies with positive, negative and varying responses to land-use change, grouped by land-use type, region and taxa.

\begin{tabular}{|c|c|c|c|c|}
\hline Land-use & Survival & Reproductive success & Movement & Response \\
\hline \multirow{3}{*}{ Agriculture } & 1 & 3 & 7 & Positive \\
\hline & 1 & 4 & 7 & Negative \\
\hline & 1 & 1 & 5 & Varies \\
\hline \multirow{3}{*}{ agmentation } & 1 & 6 & 8 & Positive \\
\hline & 2 & 7 & 9 & Negative \\
\hline & 1 & 2 & 11 & Varies \\
\hline \multirow{3}{*}{ Logging } & 1 & 2 & 3 & Positive \\
\hline & 0 & 2 & 3 & Negative \\
\hline & 0 & 0 & 1 & Varies \\
\hline \multirow{3}{*}{ Fire } & 0 & 0 & 0 & Positive \\
\hline & 0 & 0 & 1 & Negative \\
\hline & 0 & 0 & 0 & Varies \\
\hline \multirow[t]{2}{*}{ Region } & Survival & Reproductive success & Movement & Response \\
\hline & 0 & 2 & 9 & Positive \\
\hline \multirow[t]{2}{*}{ Neotropics } & 1 & 3 & 7 & Negative \\
\hline & 2 & 2 & 9 & Varies \\
\hline \multirow{3}{*}{ Afrotropics } & 1 & 4 & 2 & Positive \\
\hline & 1 & 4 & 3 & Negative \\
\hline & 0 & 0 & 1 & Varies \\
\hline \multirow{3}{*}{$\begin{array}{l}\text { ndomalayan } \\
\text { tropics }\end{array}$} & 0 & 2 & 3 & Positive \\
\hline & 0 & 2 & 2 & Negative \\
\hline & 0 & 1 & 0 & Varies \\
\hline \multirow{3}{*}{$\begin{array}{c}\text { Australasian } \\
\text { tropics/ } \\
\text { Oceania }\end{array}$} & 1 & 1 & 1 & Positive \\
\hline & 1 & 1 & 2 & Negative \\
\hline & 0 & 0 & 1 & Varies \\
\hline \multirow[t]{2}{*}{ Taxa } & Survival & Reproductive success & Movement & Response \\
\hline & 2 & 8 & 3 & Positive \\
\hline \multirow[t]{2}{*}{ Birds } & 2 & 9 & 7 & Negative \\
\hline & 1 & 2 & 9 & Varies \\
\hline & 0 & 1 & 11 & Positive \\
\hline \multirow[t]{3}{*}{ Mammals } & 1 & 1 & 6 & Negative \\
\hline & 1 & 1 & 2 & Varies \\
\hline & 0 & 0 & 0 & Positive \\
\hline \multirow[t]{2}{*}{ Reptiles } & 0 & 0 & 0 & Negative \\
\hline & 0 & 0 & 0 & Varies \\
\hline Amphibians & 0 & 0 & 1 & Positive \\
\hline
\end{tabular}




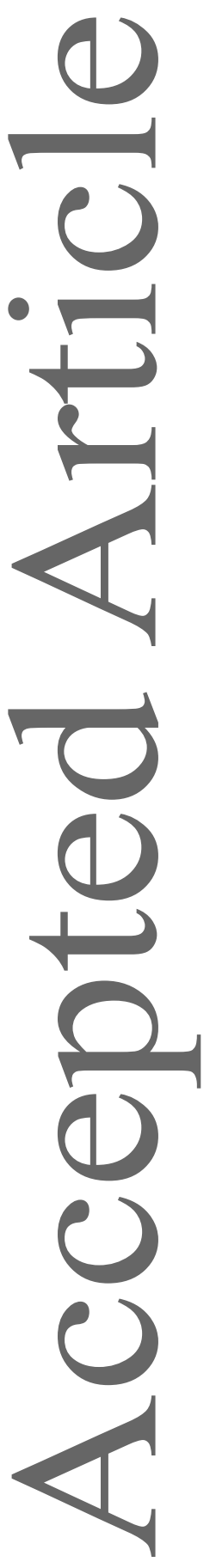


